\title{
Oxygen Surrogate Systems for Supporting Human Drug-Metabolizing Cytochrome P450 Enzymes ${ }^{\text {霖 }}$
}

\author{
Silja J. Strohmaier, James J. De Voss, Ulrik Jurva, Shalini Andersson, and Elizabeth M.J. Gillam \\ School of Chemistry and Molecular Biosciences, The University of Queensland, Brisbane, Australia (S.J.S., J.J.D.V., E.M.J.G.); and \\ DMPK, Early Cardiovascular, Renal and Metabolism (U.J.) and Discovery Sciences (S.A.), BioPharmaceuticals R\&D, AstraZeneca, \\ Gothenburg, Sweden
}

Received January 20, 2020; accepted March 12, 2020

\begin{abstract}
Oxygen surrogates (OSs) have been used to support cytochrome P450 (P450) enzymes for diverse purposes in drug metabolism research, including reaction phenotyping, mechanistic and inhibition studies, studies of redox partner interactions, and to avoid the need for NADPH or a redox partner. They also have been used in engineering P450s for more cost-effective, NADPHindependent biocatalysis. However, despite their broad application, little is known of the preference of individual P450s for different OSs or the substrate dependence of OS-supported activity. Furthermore, the biocatalytic potential of OSs other than cumene hydroperoxide $(\mathrm{CuOOH})$ and hydrogen peroxide $\left(\mathrm{H}_{2} \mathrm{O}_{2}\right)$ is yet to be explored. Here, we investigated the ability of the major human drug-metabolizing P450s, namely CYP3A4, CYP2C9, CYP2C19, CYP2D6, and CYP1A2, to use the following OSs: $\mathrm{H}_{2} \mathrm{O}_{2}$, tert-butyl hydroperoxide (tert-BuOOH), $\mathrm{CuOOH}$, (diacetoxyiodo)benzene, and bis(trifluoroacetoxy)iodobenzene. Overall, $\mathrm{CuOOH}$ and tert-BuOOH were found to be the most effective at
\end{abstract}

supporting these P450s. However, the ability of P450s to be supported by OSs effectively was also found to be highly dependent on the substrate used. This suggests that the choice of OS should be tailored to both the P450 and the substrate under investigation, underscoring the need to employ screening methods that reflect the activity toward the substrate of interest to the end application.

\section{SIGNIFICANCE STATEMENT}

Cytochrome P450 (P450) enzymes can be supported by different oxygen surrogates (OSs), avoiding the need for a redox partner and costly NADPH. However, few data exist comparing relative activity with different OSs and substrates. This study shows that the choice of OS used to support the major drug-metabolizing P450s influences their relative activity and regioselectivity in a substrate-specific fashion and provides a model for the more efficient use of P450s for metabolite biosynthesis.

\section{Introduction}

Cytochrome P450 (P450) enzymes are a superfamily of hemecontaining monooxygenases capable of mediating a variety of chemically challenging reactions on a diverse set of substrates (Guengerich, 2001, 2005; Hrycay and Bandiera, 2008, 2015; de Montellano, 2015). The human xenobiotic-metabolizing P450 enzymes are collectively responsible for $80 \%-90 \%$ of human oxidative metabolism of xenobiotics, with the major contributors being CYP3A4 (30.2\%), CYP2D6 (20\%), CYP1A2 (8.9\%), CYP2C19 (6.8\%), and CYP2C9 (12.8\%) (Zanger and Schwab, 2013). Therefore, these enzymes have been the

This work was supported by an Australian Research Council Discovery Project [Grant DP160100865] and by AstraZeneca Innovative Medicines and Early Development, Cardiovascular, Renal and Metabolism, Gothenburg. S.J.S. was funded by an International Postgraduate Research Award from the University of Queensland.

This work was presented in preliminary form at the 21st International Conference on Cytochrome P450 Biochemistry and Biophysics (Brisbane, Australia, June 2019) and Biotrans 2019 (Groningen, The Netherlands, July 2019). https://doi.org/10.1124/dmd.120.090555.

S This article has supplemental material available at dmd.aspetjournals.org. focus of efforts to determine which forms metabolize new drugs (reaction phenotyping) and the prediction of drug-drug interactions (Zanger and Schwab, 2013). Furthermore, because of their ability to act on a remarkably broad set of substrates in an often highly stereo-, chemo-, and regioselective manner, human drug-metabolizing P450s have been used as biocatalysts for the production of authentic drug metabolites (Vail et al., 2005). More recently, they have been investigated for late-stage functionalization of existing drug scaffolds (Obach et al., 2018; Fessner, 2019) and other fine chemicals. However, their direct application in metabolite production and late-stage functionalization is hindered by their often low catalytic activity and the need for a redox partner, typically cytochrome $\mathrm{P} 450$ reductase (CPR), and an expensive cofactor (NADPH), limiting the economic feasibility of P450dependent processes (Girhard et al., 2015). While whole-cell biocatalysts and in vitro cofactor regenerating systems can address the cost of cofactor provision to some degree, whole-cell systems rely on the substrate passing through the cell wall, and the reaction mixture is more complex in both cases, all of which affects subsequent product recovery.

Oxygen surrogates (OSs), such as peroxides and hypervalent iodine compounds, have been known for many years to support $\mathrm{P} 450$ activity in the absence of a redox partner and cofactor, by virtue of the peroxide

ABBREVIATIONS: CPR, cytochrome P450 reductase; $\mathrm{CuOOH}$, cumene hydroperoxide; hCPR, human NADPH-cytochrome P450 reductase; luciferin $\mathrm{H}$-EGE, ethylene glycol ester of 6'-desoxyluciferin; luciferin ME-EGE, ethylene glycol ester of luciferin 6'-methyl ether; luciferin MultiCYP, methyl ester of luciferin 6'-methyl ether; Luciferin PFBE luciferin 6'-pentafluorobenzyl ether OS, oxygen surrogate; P450, cytochrome P450; tert$\mathrm{BuOOH}$, tert-butyl hydroperoxide. 
shunt in the P450 catalytic cycle or through direct transfer of an oxygen atom to the P450 ferric heme (Hrycay and O'Brien, 1971b; Kadlubar et al., 1973; Cho et al., 2007). Various OSs have been identified to support P450 catalysis (Hrycay and O'Brien, 1971a; Hrycay et al., 1972; Kadlubar et al., 1973; Chance et al., 1979; Tan et al., 1983; Lindstrom and Aust, 1984; Hecker et al., 1987; Weiss et al., 1987; Vaz et al., 1990; Plastaras et al., 2000), including, most commonly, $\mathrm{CuOOH}$, tert$\mathrm{BuOOH}, \mathrm{H}_{2} \mathrm{O}_{2}$, and iodosylbenzene. They have been particularly used in investigations of the interactions of $\mathrm{P} 450$ s with their redox partners concerning potential allosteric effects, the mechanisms of P450 inhibition, the exploration of the P450-redox partner interaction surface, and other mechanistic questions (Guengerich et al., 1997; Keizers et al., 2005; Lin et al., 2012; Varfaj et al., 2014; Yoshimoto et al., 2016).

While the use of OSs in P450 research is well established, their application in biocatalysis has attracted attention more recently. Implementation of OSs could make P450 catalysis more economically viable. However, inherent drawbacks in the use of OSs are the rapid inactivation of the $\mathrm{P} 450$ in the presence of peroxides and other reactive OSs, and the typically low efficiency of OS-mediated monooxygenation reactions (He et al., 1998; Kumar et al., 2005, 2006). Therefore, several studies have attempted to improve the ability of P450s to use cheap OSs by directed evolution or rational engineering approaches (Joo et al., 1999; Cirino and Arnold, 2002, 2003; Keizers et al., 2005; Kumar et al., 2005, 2006; Otey et al., 2006). More recent studies have aimed to optimize conditions for using peroxides to support P450 activities, but among human drug-metabolizing P450s, only CYP3A4 and CYP2D6 have been studied in any detail. No reports have examined iodosylbenzene derivatives for biocatalytic applications with drug-metabolizing P450s (Chefson et al., 2006; Kumar et al., 2006), although they have been explored with microbial forms (Dangi et al., 2018). Therefore, we set out to perform a more systematic analysis of the five major human xenobiotic-metabolizing P450s with several different commonly available OSs to determine the most appropriate OS to use for each form for both mechanistic studies and biocatalytic applications.

\section{Methods and Materials}

Materials. The $\mathrm{pCW}$ vector from which all expression plasmids were derived was provided by Professor F.W. Dahlquist (University of Oregon, Eugene, OR). The bicistronic expression constructs $\mathrm{pCW} / \mathrm{CYP} 1 \mathrm{~A} 2 / \mathrm{hCPR}, \mathrm{pCW} / \mathrm{CYP} 2 \mathrm{C} 9 \mathrm{FL} /$ hCPR, pCW/2C19 $\mathrm{His} / \mathrm{hCPR}, \mathrm{pCW} / 2 \mathrm{D} 6$ (Variant DB11), and pCW/CYP3A4/ hCPR were constructed as previously described (Sandhu et al., 1994; Gillam et al., 1995; Richardson et al., 1995; Parikh et al., 1997; Shukla et al., 2005). For all P450s except CYP2D6, these plasmids encode an enzyme modified to encode the peptide "MALLLAVFL" in the N-terminal in place of the native hydrophobic anchor to enable expression in bacteria. For CYP2D6, the N-terminus was replaced in the expressed enzyme with the peptide "MARQVHSSWNL" upstream of the proline-rich region that marks the start of the catalytic domain. DH5 $\alpha F^{\prime}$ IQ strain cells were obtained from Life Technologies/ ThermoFisher and were pretransformed with the pGro7 plasmid, which was obtained from Dr. H. Yanagi (HSP Research Institute, Shimogyo-ku, Kyoto, Japan; Nishihara et al., 1998).

Expression of P450s. Expression of recombinant P450s in Escherichia coli and preparation of subcellular bacterial membrane fractions was performed according to established methods (Gillam et al., 1993). P450 concentrations were measured via $\mathrm{Fe}$ (II)-CO versus Fe(II) difference spectroscopy and hCPR concentrations were quantified using the cytochrome $c$ reduction assay, both performed as described by Guengerich et al. (2009).

Enzymatic Assays. All assays were conducted with bacterial membrane fractions containing $0.5 \mu \mathrm{M}$ P450 coexpressed with hCPR in $100 \mathrm{mM}$ potassium phosphate buffer ( $\mathrm{pH}$ 7.4). Reactions were initiated by the respective support system, i.e., OS or an NADPH-regenerating system [final concentrations: $100 \mathrm{mM}$ potassium phosphate buffer $(\mathrm{pH} 7.4), 0.25 \mathrm{mM} \mathrm{NADP}^{+}, 10 \mathrm{mM}$ glucose-6-phosphate, $0.5 \mathrm{U} / \mathrm{ml}$ glucose-6-phosphate dehydrogenase]. Final concentrations of OSs were $1,0.5,0.25$, and $0.1 \mathrm{mM}$. All reactions were incubated at $37^{\circ} \mathrm{C}$ for the times indicated in descriptions of individual assays below, with moderate shaking to allow aeration of samples. As a control, reactions were carried out in parallel in the absence of enzyme, which resulted in no detectable product formation in all cases. All incubations were performed according to a preset plan with three independent replicates. Except for alkoxyresorufins, which were monitored continuously, reactions for all substrates were carried out at a single high-substrate concentration and terminated at a fixed time, as our purpose was to screen for general ability to use OSs to detect broad differences between P450s rather than to compare kinetics.

Dealkylation or hydroxylation of the luminogenic substrates was measured in opaque, white 384-well plates with the luciferin derivatives at the concentrations recommended by the manufacturer $(50 \mu \mathrm{M}$ luciferin MultiCYP, $6 \mu \mathrm{M}$ luciferin 1A2, $100 \mu \mathrm{M}$ luciferin-H, $30 \mu \mathrm{M}$ luciferin ME-EGE, $10 \mu \mathrm{M}$ luciferin H-EGE, and $50 \mu \mathrm{M}$ luciferin pentafluorobenzyl ether; Promega, Madison, WI). The $20 \mu \mathrm{l}$ incubations were quenched after 60 minutes by the addition of an equal volume of the respective luminescence detection reagent. Samples were left for 20 minutes at $25^{\circ} \mathrm{C}$ to allow the development of luminescence before analysis in a luminescence detector (CLARIOstar Plus Multi-Mode Microplate Reader; BMG Labtech, Ortenberg, Germany). For assays with luminogenic substrates, the luciferin detection reagent contained luciferase (all substrates), esterase (luciferin MEEGE, luciferin H-EGE) and D-cysteine (luciferin 1A2), so the tolerance of the luciferase reaction toward applied OSs was assessed at $1 \mathrm{mM}$ of each OS. The tolerance of the esterase and luciferase in the detection reagent to OSs was tested by carrying out a CYP2D6-dependent reaction supported by NADPH/ hCPR, as described above, using luciferin ME-EGE as the substrate. The reaction, however, was quenched by adding an equal volume of $2 \mathrm{mM}$ OS. Subsequently, an equal volume (two volumes of the reaction volume) of detection reagent was added. The result was compared with a control reaction to which 0.5 volume of $100 \mathrm{mM}$ potassium phosphate buffer $(\mathrm{pH} \mathrm{7.4)}$ was added rather than OS. The same procedure was applied to test the tolerance of D-cysteine toward OSs but while using CYP1A2 and the respective substrate (luciferin-1A2) and detection reagent.

The $O$-dealkylation of 7-methoxyresorufin $(5 \mu \mathrm{M})$ was measured in a continuous assay using a Spectramax M2 microplate reader (Molecular Devices, Sunnyvale, CA) as previously described (Anari et al., 1997). Resorufin fluorescence was measured every 5 seconds over a total time of 30 minutes at excitation and emission wavelengths of 530 and $582 \mathrm{~nm}$, respectively. Initial rates were determined from the linear range with reference to a resorufin standard.

For the metabolism of diclofenac, the assay was performed as described previously with slight modifications (Strohmaier et al., 2019). Briefly, reactions were carried out in potassium phosphate buffer $(100 \mathrm{mM}, \mathrm{pH} 7.4)$ at $37^{\circ} \mathrm{C}$, using $200 \mu \mathrm{M}$ diclofenac in a final reaction volume of $200 \mu \mathrm{l}$ and were initiated with the respective support system as described above. Reactions were terminated after 60 minutes by transferring $200 \mu \mathrm{l}$ to a tube containing $50 \mu \mathrm{l}$ acetic acetonitrile [5.66\% (v/v) acetic acid in acetonitrile] and $10 \mu \mathrm{l} 1 \mathrm{mM}$-nitrocatechol (internal standard) and were processed following the same procedure as previously described (Strohmaier et al., 2019).

Caffeine metabolism and testosterone metabolism were carried out as previously described using $100 \mu \mathrm{M}$ the respective substrate (Strohmaier et al., 2019).

Assays with omeprazole were conducted in the dark with an initial concentration of $100 \mu \mathrm{M}$ omeprazole in a total reaction volume of $250 \mu \mathrm{l}$. The reactions were quenched after 60 minutes by addition of the internal standard ( $25 \mu l$ of $1 \mathrm{mM}$ progesterone) and thorough mixing with $1 \mathrm{ml}$ ethyl acetate for 1 minute. After 10 minutes centrifugation at $18,000 \mathrm{~g}, 800 \mu \mathrm{l}$ of the organic phase was transferred to a clean tube and evaporated to dryness under nitrogen. The dried extracts were resuspended in $24 \mu \mathrm{l}$ acetonitrile, followed by the addition of $76 \mu l$ highly purified water immediately prior to analysis. Samples were analyzed using a $150 \mathrm{~mm} \times 5 \mu \mathrm{M} \mathrm{C} 18$ column (Agilent, Santa Clara, CA) at a flow rate of $1.5 \mathrm{ml} / \mathrm{min}$ using a gradient from $24 \%$ to $63 \%$ acetonitrile in water over 18 minutes. Metabolites were detected by absorbance at $302 \mathrm{~nm}$.

The hydroxylation of midazolam was carried out with $300 \mu \mathrm{M}$ midazolam in a total reaction volume of $250 \mu \mathrm{l}$. After 60 minutes, $25 \mu 11 \mathrm{mM}$ nordazepam was added, and the reactions were quenched by the addition of $1 \mathrm{ml}$ ethyl acetate with subsequent extraction followed by phase separation by centrifugation at $18,000 \mathrm{~g}$ for 10 minutes. High-performance liquid chromatography analysis was conducted as previously described (Hunter et al., 2011). 
CYP1A2

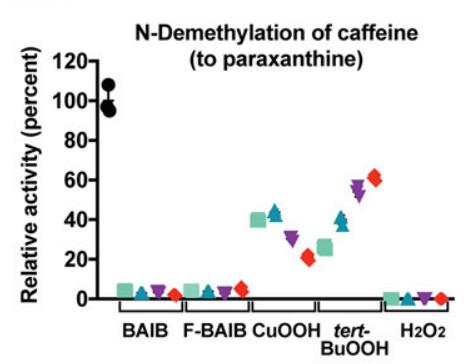

CYP2C9

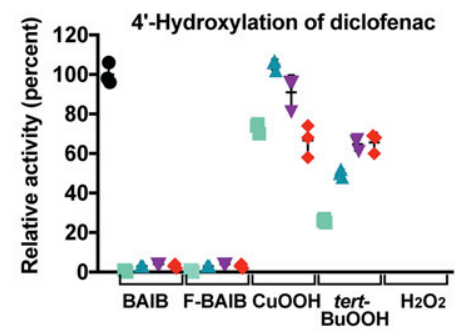

CYP2C19

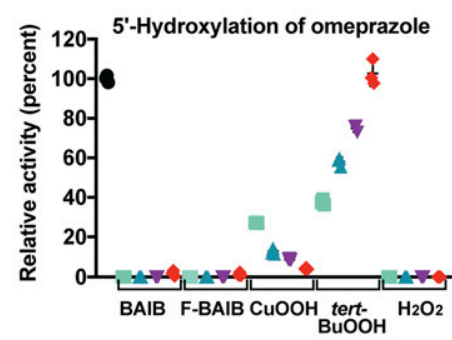

CYP2D6

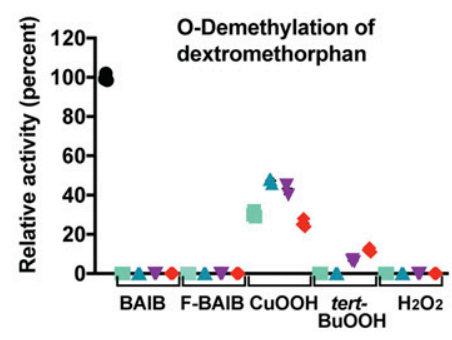

CYP3A4

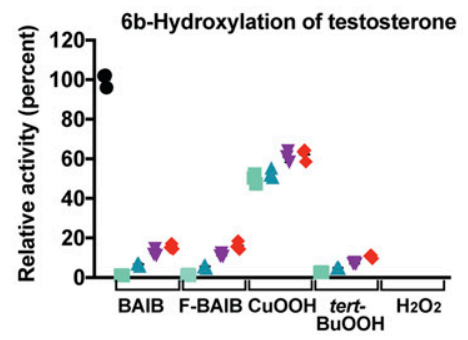

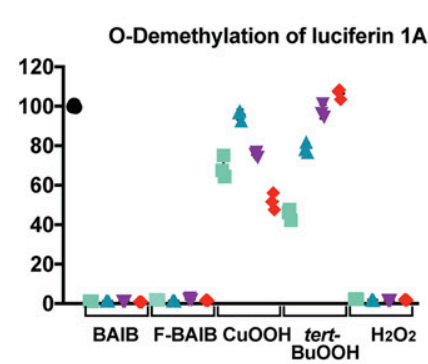
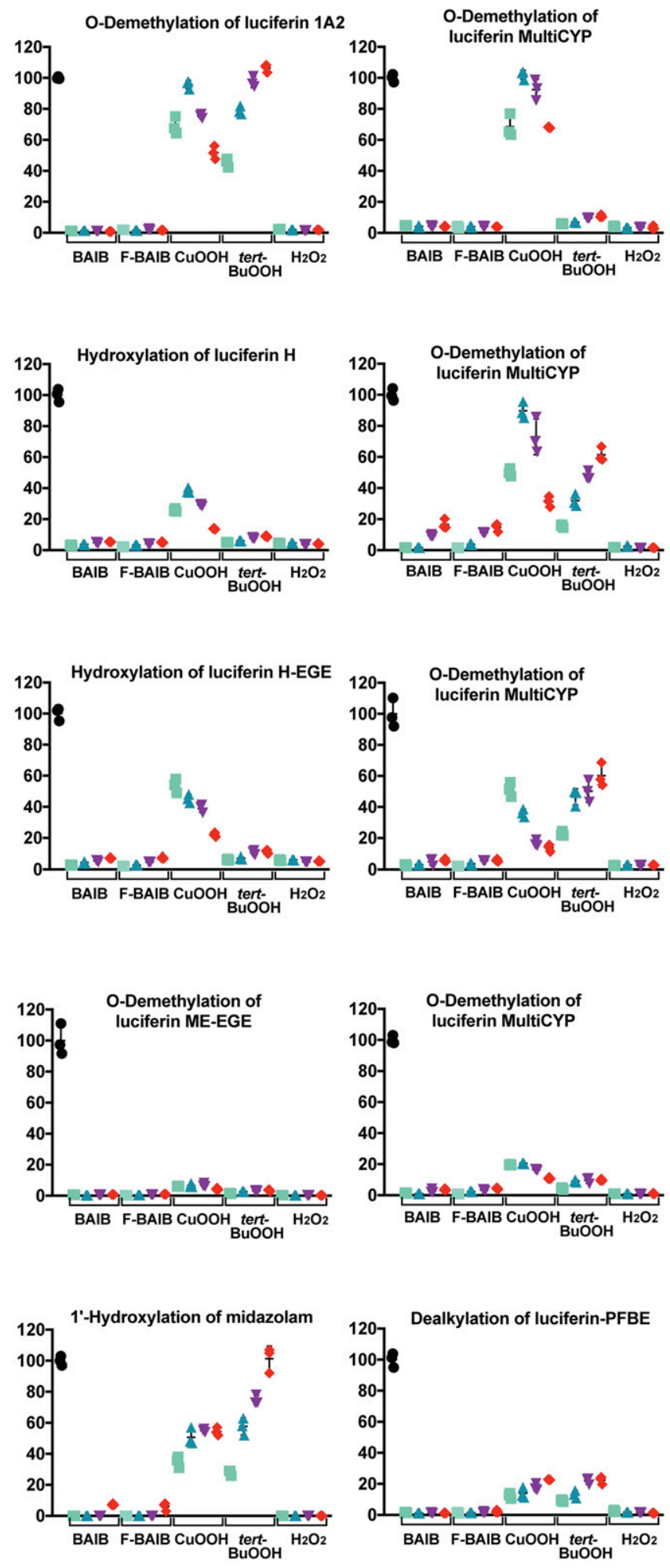

Oxygen surrogate

$0.1 \mathrm{mM} \triangle 0.25 \mathrm{mM} \nabla 0.5 \mathrm{mM} \diamond 1 \mathrm{mM}$

- NADPH / hCPR / 02

Fig. 1. OSs support the activity of the major drug-metabolizing P450s in a substrate and OS-specific manner. The major drug-metabolizing P450s were incubated with the substrates indicated in the presence of an NADPH-generating system (black circles) or one of the following four concentrations of each OS: 0.1 (light blue squares), 0.25 (blue triangles), 0.5 (purple inverted triangles), and $1 \mathrm{mM}$ (red diamonds). Incubations were carried out for 60 minutes and at the substrate concentrations as follow: $50 \mu \mathrm{M}$ luciferin MultiCYP, $6 \mu \mathrm{M}$ luciferin 1A2, $100 \mu \mathrm{M}$ luciferin-H, $30 \mu \mathrm{M}$ luciferin ME-EGE, $10 \mu \mathrm{M}$ luciferin H-EGE, $50 \mu \mathrm{M}$ luciferin PFBE, $200 \mu \mathrm{M}$ diclofenac, $100 \mu \mathrm{M}$ caffeine, $100 \mu \mathrm{M}$ testosterone, $100 \mu \mathrm{M}$ omeprazole, $300 \mu \mathrm{M}$ midazolam, and $100 \mu \mathrm{M}$ dextromethorphan. Product formation is shown relative to the activity supported by hCPR and the NADPH generating system (set to 100\%). Individual replicates are shown along with the means \pm S.D. of three replicate incubations. 
A Caffeine metabolism by CYP1A2

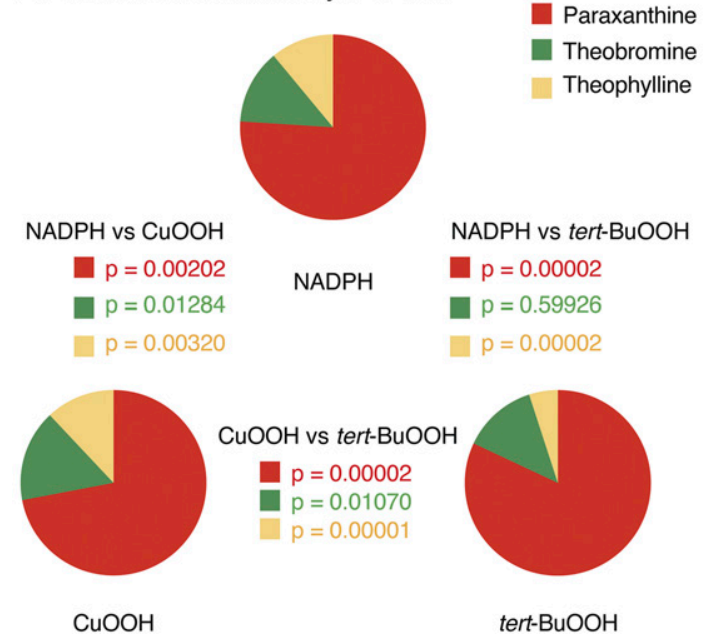

B Midazolam metabolism by CYP3A4

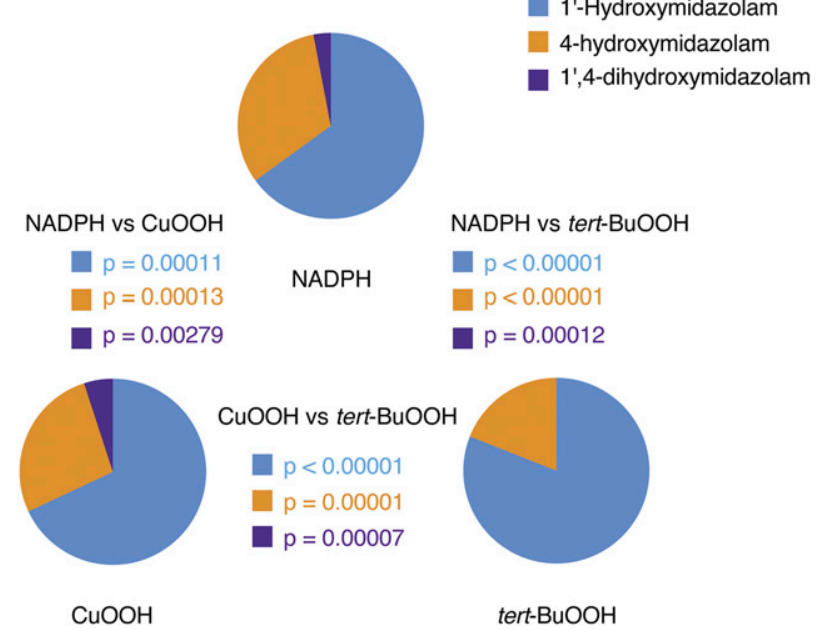

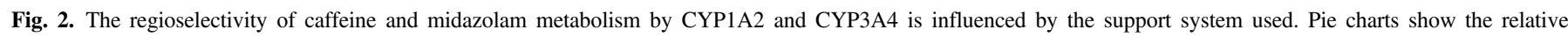

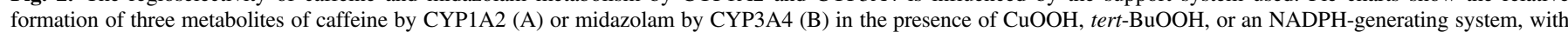

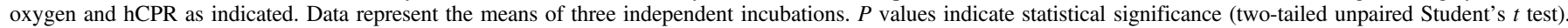

Dextromethorphan metabolism was assayed at $100 \mu \mathrm{M}$ dextromethorphan. Reactions were terminated after 60 minutes by the addition of $25 \mu l$ of $1 \mathrm{mM}$ $p$-nitrocatechol and thorough mixing with $1 \mathrm{ml}$ ethyl acetate followed by phase separation by centrifugation at $18,000 \mathrm{~g}$ for 10 minutes. Subsequent analysis was performed according to a previously described method (Gumulya et al., 2019).

\section{Results and Discussion}

Five commercially available, inexpensive OSs were studied here: $\mathrm{H}_{2} \mathrm{O}_{2}$, tert-BuOOH, $\mathrm{CuOOH}$, (diacetoxyiodo)benzene, and bis(trifluoroacetoxy)iodobenzene. Overall, organic hydroperoxides were most effective at supporting P450-mediated activity, while much lower activity, if any, was observed with $\mathrm{H}_{2} \mathrm{O}_{2}$ or the iodosylbenzene derivatives studied (Fig. 1). This may be due to rapid inactivation of the P450s by such OSs, as observed in other studies (Gustafsson et al., 1979; He et al., 1998; Yoshimoto et al., 2016; Albertolle et al., 2017). The optimal concentration of OS for supporting each P450 was consistent across multiple substrates. Generally, product formation was highest with the lower concentrations of $\mathrm{CuOOH}$, either $0.1 \mathrm{mM}$ (CYP2C19) or $0.25 \mathrm{mM} \mathrm{CuOOH} \mathrm{(CYP1A2,} \mathrm{CYP2C9,} \mathrm{and} \mathrm{CYP2D6),}$ but CYP3A4 showed a slight increase in metabolite formation at 0.5 and $1 \mathrm{mM}$. By contrast, tert-BuOOH-supported activity was maximal at the highest concentration tested here in all cases, suggesting a less effective association between the ferric heme and tert-BuOOH and/or enhanced resistance of the $\mathrm{P} 450$ s toward oxidative damage by tert- $\mathrm{BuOOH}$ compared with $\mathrm{CuOOH}$.

The activities of CYP3A4 and CYP2D6 supported by tert-BuOOH and $\mathrm{CuOOH}$ in our study were lower relative to the NADPH-supported control than those reported previously by Chefson et al. (2006). One key difference between the present and previous studies was that NADPH was used directly in Chefson et al. (2006), whereas an NADPHregenerating system was used here. NADPH is usually rapidly converted in $\mathrm{P} 450$ reactions to $\mathrm{NADP}^{+}$, which can inhibit CPR. Thus, this may have led to lower activity of the control in the study reported by Chefson et al. (2006). Alternatively, differences in the P450:CPR ratio or other incubation conditions between ours and the earlier study may have caused the discrepancy.

In the present study, hydrogen peroxide was the least effective OS overall, which agrees with several other studies on microsomal P450s reported previously (Kadlubar et al., 1973, 2005; Chefson et al., 2006). CYP1A2-mediated 7-methoxyresorufin $O$-demethylase activity in liver microsomes was reported to be supported effectively by $\mathrm{H}_{2} \mathrm{O}_{2}$ (Anari et al., 1997); however, we were unable to confirm this result using recombinant human CYP1A2 (Supplemental Fig. 1). CYP3A4-dependent N-oxide formation from quinidine was reported to be comparable between reactions supported by $\mathrm{H}_{2} \mathrm{O}_{2}$ and $\mathrm{NADPH} / \mathrm{CPR} / \mathrm{O}_{2}$ (Guengerich and Johnson, 1997). Similarly, CYP2B1 and CYP2B4 metabolized $\mathrm{N}, \mathrm{N}$-dimethylaniline to the corresponding $\mathrm{N}$-oxide equally effectively in the presence of $\mathrm{H}_{2} \mathrm{O}_{2}$ as in reactions supported by NADPH (Guengerich and Johnson, 1997). Collectively, this suggests that the ability of $\mathrm{H}_{2} \mathrm{O}_{2}$ to support activity may depend to some extent on the type of the reaction. Notably, no $\mathrm{N}$-oxidation reactions were included among the activities studied in this work.

For most substrates, only a single significant metabolite could be detected (as shown in Fig. 1); however, for caffeine metabolism by CYP1A2 and midazolam metabolism by CYP3A4, multiple products were detected at measurable levels (Fig. 2). We cannot exclude the possibility that additional metabolites may have been formed from alkoxyresorufins and luciferin derivatives, but to our knowledge, there is no precedent for alternative metabolites not detectable by the methods used. The regioselectivity of midazolam and caffeine metabolism was altered slightly but significantly when using organic peroxides compared with NADPH/CPR-supported reactions (Fig. 2; Supplemental Tables 1 and 2). Similar observations have been made previously with various P450s and diverse substrates (Hrycay et al., 1975; Hanna et al., 2001; Yoshimoto et al., 2016; Dangi et al., 2018). This phenomenon is generally explained by a greater tendency of these OSs to undergo homolytic O-O bond scission as compared with $\mathrm{H}_{2} \mathrm{O}_{2}$ because of electron donating substituents (White and Coon, 1980; Barr et al., 1996; Nam et al., 2000). This may result in a mechanism in which hydrogen abstraction from the substrate is mediated by the resulting alkoxy radical rather than by compound I (White and Coon, 1980; Blake and Coon, 1981; Weiss and Estabrook, 1986). Therefore, the changes in regioselectivity observed may be related to the different positioning of the alkoxy radical and compound I relative to the substrate.

Overall, for each isoform, the relative activity supported by the OSs differed according to which substrate was used to evaluate activity. This phenomenon was particularly pronounced in case of 
tert-BuOOH-supported metabolism. This observation that relative activity differs in a substrate-dependent fashion is consistent with a previous study in which the $K_{\mathrm{M}}^{\mathrm{CuOOH}}$ of CYP3A4 differed with different substrates (Kumar et al., 2006). The authors speculated that the active site could be masked to a greater or lesser extent, depending on the substrate, hampering access of the OS to the heme and resulting in substrate-dependent changes of the $K_{\mathrm{M}}^{\mathrm{CuOOH}}$. In such a scenario, a sterically less complex, albeit hydrophobic OS (i.e., tert-BuOOH), would have better access to the active site than a larger one (i.e., $\mathrm{CuOOH}$ ). If accessibility of the OS was diminished by a larger hydroperoxide, one might expect that the relative activity with, e.g., $\mathrm{CuOOH}$ would be affected to a larger extent than that supported by a simpler peroxide (e.g., tert-BuOOH) in the presence of different substrates. If hydrogen abstraction from the substrate is mediated by the resulting alkoxy radical rather than by compound $\mathrm{I}$, the orientations of the substrate and OS relative to the heme in the active site may determine the relative effectiveness of hydrogen abstraction by the OS-derived alkoxy radical and subsequent substrate monooxygenation by oxygen rebound from the heme. No metabolite formation was observed for any of the OSs in the absence of a P450, ruling out the possibility that purely chemical reactions contribute to the differences seen.

We also considered whether the remnant of the OS may have affected the orientation or accessibility of the substrate to the heme, leading to increased or decreased turnover. However, addition of $1 \mathrm{mM}$ tertbutanol to the NADPH/CPR-supported incubations of CYP3A4 with testosterone and midazolam affected neither product formation nor stereoselectivity (data not shown), suggesting that such an effect is unlikely.

In conclusion, this study has revealed that the organic peroxides, $\mathrm{CuOOH}$ and tert-BuOOH, are the best starting points for supporting activity of the major drug-metabolizing P450s in the absence of $\mathrm{NADPH}$, molecular oxygen, or a redox partner, but the relative activity supported by OSs is substrate-dependent. Further studies will be necessary to explore the nature of this phenomenon. The potential for alterations in regioselectivity of substrate oxidation should be considered when OSs are used for mechanistic studies. Likewise, when OSs are used to support the activity of P450s for biocatalysis, the OS used should be tailored to both the P450 and the substrate under investigation, underscoring the need to employ screening methods that reflect the activity toward the substrate of interest to the end application.

\section{Authorship Contributions}

Participated in research design: Strohmaier, Gillam.

Conducted experiments: Strohmaier.

Contributed new reagents or analytic tools: De Voss, Jurva, Andersson.

Performed data analysis: Strohmaier, Gillam.

Wrote or contributed to the writing of the manuscript: Strohmaier, De Voss, Jurva, Andersson, Gillam.

\section{References}

Albertolle ME, Kim D, Nagy LD, Yun C-H, Pozzi A, Savas Ü, Johnson EF, and Guengerich FP (2017) Heme-thiolate sulfenylation of human cytochrome P450 4A11 functions as a redox switch for catalytic inhibition. J Biol Chem 292:11230-11242.

Anari MR, Josephy PD, Henry T, and O'Brien PJ (1997) Hydrogen peroxide supports human and rat cytochrome P450 1A2-catalyzed 2-amino-3-methylimidazo[4,5-f]quinoline bioactivation to mutagenic metabolites: significance of cytochrome $\mathrm{P} 450$ peroxygenase. Chem Res Toxicol 10: 582-588.

Barr DP, Martin MV, Guengerich FP, and Mason RP (1996) Reaction of cytochrome P450 with cumene hydroperoxide: ESR spin-trapping evidence for the homolytic scission of the peroxide $\mathrm{O}-\mathrm{O}$ bond by ferric cytochrome P450 1A2. Chem Res Toxicol 9:318-325.

Blake RC II and Coon MJ (1981) On the mechanism of action of cytochrome P-450. Evaluation of homolytic and heterolytic mechanisms of oxygen-oxygen bond cleavage during substrate hydroxylation by peroxides. J Biol Chem 256:12127-12133.

Chance B, Sies H, and Boveris A (1979) Hydroperoxide metabolism in mammalian organs. Physiol Rev 59:527-605.
Chefson A, Zhao J, and Auclair K (2006) Replacement of natural cofactors by selected hydrogen peroxide donors or organic peroxides results in improved activity for CYP3A4 and CYP2D6. ChemBioChem 7:916-919.

Cho KB, Moreau Y, Kumar D, Rock DA, Jones JP, and Shaik S (2007) Formation of the active species of cytochrome p450 by using iodosylbenzene: a case for spin-selective reactivity. Chemistry 13:4103-4115.

Cirino PC and Arnold FH (2002) Regioselectivity and activity of cytochrome P450 BM-3 and mutant F87A in reactions driven by hydrogen peroxide. Adv Synth Catal 344:932-937.

Cirino PC and Arnold FH (2003) A self-sufficient peroxide-driven hydroxylation biocatalyst. Angew Chem Int Ed Engl 42:3299-3301.

Dangi B, Park H, and Oh TJ (2018) Effects of alternative redox partners and oxidizing agents on CYP154C8 catalytic activity and product distribution. ChemBioChem 19:2273-2282.

de Montellano PRO (2015) Substrate oxidation by cytochrome P450 enzymes, in Cytochrome P450; Structure, Mechanism, and Biochemistry (Ortiz de Montellano PR ed) pp 111-176, Springer.

Fessner ND (2019) P450 Monooxygenases enable rapid late-stage diversification of natural products via C-H bond activation. ChemCatChem 11:2226-2242

Gillam EMJ, Baba T, Kim B-R, Ohmori S, and Guengerich FP (1993) Expression of modified human cytochrome P450 3A4 in Escherichia coli and purification and reconstitution of the enzyme. Arch Biochem Biophys 305:123-131.

Gillam EMJ, Guo Z, Martin MV, Jenkins CM, and Guengerich FP (1995) Expression of cytochrome P450 2D6 in Escherichia coli, purification, and spectral and catalytic characterization. Arch Biochem Biophys 319:540-550.

Girhard M, Bakkes PJ, Mahmoud O, and Urlacher VB (2015) P450 biotechnology, in Cytochrome P450. Structure, Mechanism, and Biochemistry (Ortiz de Montellano PR ed) pp 451-520, Springer International Publishing, Cham, Switzerland.

Guengerich FP (2001) Common and uncommon cytochrome P450 reactions related to metabolism and chemical toxicity. Chem Res Toxicol 14:611-650.

Guengerich FP (2005) Human cytochrome P450 enzymes, in Cytochrome P450 (Ortiz de Montellano PR ed) pp 377-530, Kluwer Academic/Plenum Publishing, New York

Guengerich FP and Johnson WW (1997) Kinetics of ferric cytochrome P450 reduction by NADPH-cytochrome P450 reductase: rapid reduction in the absence of substrate and variations among cytochrome P450 systems. Biochemistry 36:14741-14750.

Guengerich FP, Martin MV, Sohl CD, and Cheng Q (2009) Measurement of cytochrome P450 and NADPH-cytochrome P450 reductase. Nat Protoc 4:1245-1251.

Guengerich FP, Vaz AD, Raner GN, Pernecky SJ, and Coon MJ (1997) Evidence for a role of a perferryl-oxygen complex, $\mathrm{FeO}^{3+}$, in the N-oxygenation of amines by cytochrome $\mathrm{P} 450$ enzymes. Mol Pharmacol 51:147-151.

Gumulya Y, Huang W, D'Cunha SA, Richards KE, Thomson RES, Hunter DJB, Baek J-M, Harris KL, Boden M, De Voss JJ, et al. (2019) Engineering thermostable CYP2D enzymes for biocatalysis using combinatorial libraries of ancestors for directed evolution (CLADE). ChemCatChem 11:841-850.

Gustafsson JÅ, Rondahl L, and Bergman J (1979) Iodosylbenzene derivatives as oxygen donors in cytochrome P-450 catalyzed steroid hydroxylations. Biochemistry 18:865-870.

Hanna IH, Krauser JA, Cai H, Kim M-S, and Guengerich FP (2001) Diversity in mechanisms of substrate oxidation by cytochrome P450 2D6. Lack of an allosteric role of NADPH-cytochrome P450 reductase in catalytic regioselectivity. $J$ Biol Chem 276:39553-39561.

He K, Bornheim LM, Falick AM, Maltby D, Yin H, and Correia MA (1998) Identification of the heme-modified peptides from cumene hydroperoxide-inactivated cytochrome P450 3A4. Biochemistry 37:17448-17457.

Hecker M, Baader WJ, Weber P, and Ullrich V (1987) Thromboxane synthase catalyses hydroxylations of prostaglandin $\mathrm{H} 2$ analogs in the presence of iodosylbenzene. Eur J Biochem 169: $563-569$

Hrycay EG and Bandiera SM (2008) Cytochrome P450 enzymes, in Preclinical Development Handbook: ADME and Biopharmaceutical Properties (Gad SC ed) pp 627-696, Wiley, Hoboken, NJ.

Hrycay EG and Bandiera SM (2015) Monooxygenase, peroxidase and peroxygenase properties and reaction mechanisms of cytochrome $\mathrm{P} 450$ enzymes, in Monooxygenase, Peroxidase and Peroxygenase Properties and Mechanisms of Cytochrome P450 (Hrycay EG and Bandiera SM eds), pp 1-61, Springer International Publishing, Cham, Switzerland.

Hrycay EG, Gustafsson JA, Ingelman-Sundberg M, and Ernster L (1975) Sodium periodate, sodium chloride, organic hydroperoxides, and $\mathrm{H} 2 \mathrm{O} 2$ as hydroxylating agents in steroid hydroxylation reactions catalyzed by partially purified cytochrome P-450. Biochem Biophys Res Commun 66:209-216.

Hrycay EG and O'Brien PJ (1971a) Cytochrome P-450 as a microsomal peroxidase utilizing a lipid peroxide substrate. Arch Biochem Biophys 147:14-27.

Hrycay EG and O'Brien PJ (1971b) The peroxidase nature of cytochrome P-420 utilizing a lipid peroxide substrate. Arch Biochem Biophys 147:28-35.

Hrycay EC, O'Brein PJ, Van Lier JE, and Kan G (1972) Pregnene 17 -hydroperoxides as possible precursors of the adrenosteroid hormones. Arch Biochem Biophys 153:495-501.

Hunter DJB, Behrendorff JBYH, Johnston WA, Hayes PY, Huang W, Bonn B, Hayes MA, De Voss JJ, and Gillam EMJ (2011) Facile production of minor metabolites for drug development using a CYP3A shuffled library. Metab Eng 13:682-693.

Joo H, Lin Z, and Arnold FH (1999) Laboratory evolution of peroxide-mediated cytochrome P450 hydroxylation. Nature 399:670-673.

Kadlubar FF, Morton KC, and Ziegler DM (1973) Microsomal-catalyzed hydroperoxide-dependent C-oxidation of amines. Biochem Biophys Res Commun 54:1255-1261.

Keizers PH, Schraven LH, de Graaf C, Hidestrand M, Ingelman-Sundberg M, van Dijk BR, Vermeulen NP, and Commandeur JN (2005) Role of the conserved threonine 309 in mechanism of oxidation by cytochrome P450 2D6. Biochem Biophys Res Commun 338 $1065-1074$

Kumar S, Chen CS, Waxman DJ, and Halpert JR (2005) Directed evolution of mammalian cytochrome P450 2B1: mutations outside of the active site enhance the metabolism of severa substrates, including the anticancer prodrugs cyclophosphamide and ifosfamide. J Biol Chem 280:19569-19575.

Kumar S, Liu H, and Halpert JR (2006) Engineering of cytochrome P450 3A4 for enhanced peroxide-mediated substrate oxidation using directed evolution and site-directed mutagenesis. Drug Metab Dispos 34:1958-1965.

Lin HL, Kenaan C, Zhang H, and Hollenberg PF (2012) Reaction of human cytochrome P450 3A4 with peroxynitrite: nitrotyrosine formation on the proximal side impairs its interaction with NADPH-cytochrome P450 reductase. Chem Res Toxicol 25:2642-2653. 
Lindstrom TD and Aust SD (1984) Studies on cytochrome P-450-dependent lipid hydroperoxide reduction. Arch Biochem Biophys 233:80-87.

Nam W, Han HJ, Oh S-Y, Lee YJ, Choi M-H, Han S-Y, Kim C, Woo SK, and Shin W (2000) New insights into the mechanisms of $\mathrm{O}-\mathrm{O}$ Bond cleavage of hydrogen peroxide and tert-alkyl hydroperoxides by iron(III) porphyrin complexes. J Am Chem Soc 122:8677-8684.

Nishihara K, Kanemori M, Kitagawa M, Yanagi H, and Yura T (1998) Chaperone coexpression plasmids: differential and synergistic roles of DnaK-DnaJ-GrpE and GroEL-GroES in assisting folding of an allergen of Japanese cedar pollen, Cryj2, in Escherichia coli. Appl Environ Microbiol 64:1694-1699.

Obach RS, Walker GS, Sharma R, Jenkinson S, Tran TP, and Stepan AF (2018) Lead diversification at the nanomole scale using liver microsomes and quantitative nuclear magnetic resonance spectroscopy: application to phosphodiesterase 2 inhibitors. J Med Chem 61:3626-3640.

Otey CR, Bandara G, Lalonde J, Takahashi K, and Arnold FH (2006) Preparation of human metabolites of propranolol using laboratory-evolved bacterial cytochromes P450. Biotechnol Bioeng 93:494-499.

Parikh A, Gillam EMJ, and Guengerich FP (1997) Drug metabolism by Escherichia coli expressing human cytochromes P450. Nat Biotechnol 15:784-788.

Plastaras JP, Guengerich FP, Nebert DW, and Marnett LJ (2000) Xenobiotic-metabolizing cytochromes P450 convert prostaglandin endoperoxide to hydroxyheptadecatrienoic acid and the mutagen, malondialdehyde. J Biol Chem 275:11784-11790.

Richardson TH, Jung F, Griffin KJ, Wester M, Raucy JL, Kemper B, Bornheim LM, Hassett C, Omiecinski CJ, and Johnson EF (1995) A universal approach to the expression of human and rabbit cytochrome P450s of the 2C subfamily in Escherichia coli. Arch Biochem Biophys 323:87-96.

Sandhu P, Guo Z, Baba T, Martin MV, Tukey RH, and Guengerich FP (1994) Expression of modified human cytochrome P450 1A2 in Escherichia coli: stabilization, purification, spectral characterization, and catalytic activities of the enzyme. Arch Biochem Biophys 309:168-177.

Shukla A, Gillam EM, Mitchell DJ, and Bernhardt PV (2005) Direct electrochemistry of enzymes from the cytochrome P450 2C family. Electrochem Commun 7:437-442.

Strohmaier SJ, Huang W, Baek J-M, Hunter DJB, and Gillam EMJ (2019) Rational evolution of the cofactor-binding site of cytochrome P450 reductase yields variants with increased activity towards specific cytochrome P450 enzymes. FEBS J 286:4473-4493.
Tan L, Hrycay EG, and Matsumoto K (1983) Synthesis and properties of the epimeric 6hydroperoxyandrostenediones, new substrates/inhibitors of human placental aromatase. J Steroid Biochem 19:1329-1338.

Vail RB, Homann MJ, Hanna I, and Zaks A (2005) Preparative synthesis of drug metabolites using human cytochrome P450s 3A4, 2C9 and 1A2 with NADPH-P450 reductase expressed in Escherichia coli. J Ind Microbiol Biotechnol 32:67-74.

Varfaj F, Zulkifli SNA, Park H-G, Challinor VL, De Voss JJ, and Ortiz de Montellano PR (2014) Carbon-carbon bond cleavage in activation of the prodrug nabumetone. Drug Metab Dispos 42: 828-838.

Vaz AD, Roberts ES, and Coon MJ (1990) Reductive beta-scission of the hydroperoxides of fatty acids and xenobiotics: role of alcohol-inducible cytochrome P-450. Proc Natl Acad Sci USA 87 $5499-5503$.

Weiss RH, Arnold JL, and Estabrook RW (1987) Transformation of an arachidonic acid hydroperoxide into epoxyhydroxy and trihydroxy fatty acids by liver microsomal cytochrome P-450. Arch Biochem Biophys 252:334-338.

Weiss RH and Estabrook RW (1986) The mechanism of cumene hydroperoxide-dependent lipid peroxidation: the function of cytochrome P-450. Arch Biochem Biophys 251:348-360.

White RE and Coon MJ (1980) Oxygen activation by cytochrome P-450. Annu Rev Biochem 49 315-356.

Yoshimoto FK, Gonzalez E, Auchus RJ, and Guengerich FP (2016) Mechanism of 17 $\alpha, 20$-lyase and new hydroxylation reactions of human cytochrome P450 17A $1:{ }^{18} \mathrm{O}$ labeling and oxygen surrogate evidence for a role of a perferryl oxygen. J Biol Chem 291:17143-17164.

Zanger UM and Schwab M (2013) Cytochrome P450 enzymes in drug metabolism: regulation of gene expression, enzyme activities, and impact of genetic variation. Pharmacol Ther 138:103-141.

Address correspondence to: Elizabeth M.J. Gillam, School of Chemistry and Molecular Biosciences, The University of Queensland, St. Lucia, Brisbane 4072, Australia. E-mail: e.gillam@uq.edu.au 